\title{
SUBSTRATOS ORGÂNICOS PARA A PRODUÇÃO DE MUDAS DE Tectona grandis L. f. EM CAPITÃO POÇO - PA
}

\section{ORGANIC SUBSTRATES FOR THE PRODUCTION OF CHANGES OF Tectona grandis L. f. IN CAPITÃO POÇO - PA}

\author{
Nathalia Sousa Braga ${ }^{1}$; Bianca Machado de Lima²; Eglison Souza Barbosa ${ }^{3}$ Jamilie Brito de \\ Castro $^{4}$; Raimundo Thiago Lima da Silva ${ }^{5}$
}

DOI: https://doi.org/10.31692/978-65-991061-7-0.202-211

\section{RESUMO}

Para o adequado estabelecimento das espécies florestais, é necessário que o solo permita o crescimento das raízes, o fornecimento de água e nutrientes e as trocas gasosas. Assim, o trabalho teve como objetivo avaliar o efeito dos substratos orgânicos na qualidade física da muda visando à implantação de um povoamento de Tectona grandis L. em Capitão Poço PA. Os tratamentos foram compostos pelas proporções serragem (SC), terra de subsolo (TS), esterco bovino (EB), cama de frango (CF). (SC:TS:EB:CF:): T1 (25:40:35:00); T2 (25:50:25:00); T3 (25:40:00:35); T4 (25:50:00:25). constituído por 4 tratamentos, com 49 repetições por tratamento sendo cada repetição constituída por uma planta. Foi determinada a análise química dos tratamentos no Laboratório da Embrapa Amazônia Oriental, Belém, PA. Observou-se que o uso de esterco bovino e cama de frango como componente de substrato proporcionou efeito significativo $(\mathrm{p}<0,05)$ para as variáveis: altura da parte aérea, número de folhas e diâmetro do coleto. Com exceção para o número de folhas que foram estatisticamente iguais nos 151 dias após a semeadura (DAS). As mudas apresentaram crescimento médio em altura entre 5,24 a 10,97; 6,95 a 12,62; 8,2 a 13,44 $\mathrm{cm}_{\text {planta }}{ }^{-1}$ para os períodos de $91,121 \mathrm{e}$ 151 DAS, respectivamente. O crescimento em diâmetro das mudas de teca variou de 0,39 a 0,$63 ; 0,34$ a 0,$51 ; 0,41$ a $0,57 \mathrm{~cm}$ planta $^{-1}$ nos períodos de 91, 121 e 151 DAS, respectivamente. O número das folhas das mudas de teca variou de 5,08 a 6,89; 5,73 a 5,95; 4,84 a 6,5 nos períodos de 91, 121 e 151 DAS, respectivamente. A massa aérea das mudas de teca variou de 2,41 a $4,55 \mathrm{~g}_{\text {planta }}{ }^{-1}$. A massa seca radicular das mudas de teca variou de 1,45 a 2,51 $\mathrm{g} \mathrm{planta}^{-1}$. Para a massa seca total, as mudas alcançaram valores entre 2,91 a $5,02 \mathrm{~g}$ planta $^{-1}$, e os valores de IQD das mudas de teca alcançaram valores entre 0,14 a 0,23 . Portanto, tem-se que as plantas mais desenvolvidas foram produzidas no tratamento T4 composto de $25 \%$ de serragem $+50 \%$ de subsolo $+25 \%$ de esterco de frango.

Palavras-Chave: Tectona grandis L., esterco bovino, cama de frango.

\section{ABSTRACT}

For the proper establishment of the forest species, it is necessary that the soil allows the growth of the roots, the supply of water and nutrients and the gas exchanges. The objective of this work was to evaluate the effect of the organic substrates on the physical quality of the seedling, aiming at the implantation of a settlement of Tectona grandis L. in Capitão Poço PA. The treatments were composed of sawdust (SC), subsoil soil (TS), bovine manure (EB), chicken bed (CF). (SC: TS: EB: CF :): T1 (25: 40: 35: 00); T2 (25: 50: 25: 00); T3 (25: 40: 00: 35); T4 (25: 50: 00: 25). consisting of 4 treatments, with 49 replicates per treatment, each

\footnotetext{
${ }^{1}$ Engenharia Florestal, Universidade Federal Rural da Amazônia, nathalia.eng.flor@gmail.com.

${ }^{2}$ Agronomia, Universidade Federal Rural da Amazônia, bianca.agro96@gmail.com.

${ }^{3}$ Engenharia Florestal, Universidade Federal Rural da Amazônia, eglisontecflor@gmail.com.

${ }^{4}$ Engenharia Florestal, Universidade Federal Rural da Amazônia, jamiliejbc@ gmail.com.

5 Professor Dr., Universidade Federal Rural da Amazônia, thiagoufra@ hotmail.com.
} 
replicate consisting of one plant. The chemical analysis of the treatments at the Embrapa Amazônia Oriental Laboratory, Belém, PA, was determined. It was observed that the use of bovine manure and chicken litter as a substrate component provided a significant effect ( $\mathrm{p}$ $<0.05)$ for the variables: shoot height, leaf number and collection diameter. Except for the number of leaves that were statistically the same at 151 days after sowing (DAS). The seedlings presented a mean growth in height between 5.24 and $10.97 ; 6.95$ to $12.62 ; 8.2$ to $13.44 \mathrm{~cm}$ plant-1 for the periods 91,121 and 151 DAS, respectively. The growth in diameter of the teak seedlings ranged from 0.39 to $0.63 ; 0.34$ to $0.51 ; 0.41$ to $0.57 \mathrm{~cm}$ plant -1 in the periods of 91, 121 and 151 DAS, respectively. The number of leaves of the teak seedlings ranged from 5.08 to $6.89 ; 5.73$ to $5.95 ; 4.84$ to 6.5 in the 91,121 and 151 DAS periods, respectively. The aerial mass of the teak seedlings ranged from 2.41 to $4.55 \mathrm{~g}$ plant -1 . The root dry mass of the teak seedlings ranged from 1.45 to $2.51 \mathrm{~g}$ plant-1. For the total dry mass, the seedlings reached values between 2.91 and $5.02 \mathrm{~g}$ plant-1, and the IQD values of the teak seedlings reached values between 0.14 and 0.23 . Therefore, it has been found that the more developed plants were produced in the T4 treatment composed of $25 \%$ sawdust $+50 \%$ of subsoil $+25 \%$ of chicken manure.

Keywords: Tectona grandis L., cattle manure, chicken bed.

\section{INTRODUÇÃO}

A teca (Tectona grandis L.f.) é uma espécie arbórea decídua, pertencente à família Lamiaceae (MISSOURI BOTANICAL GARDEN, 2013). A crescente demanda madeireira associada à exploração intensiva comprometeu os estoques das florestas nativas, evidenciando a necessidade de estudos para aumentar a produção de madeira a partir de florestas plantadas, a teca possui grande importância na economia no contexto mundial, pois produz uma madeira com excelente qualidade estética, boa resistência, estabilidade dimensional e durabilidade (BEZERRA et al., 2011; ÂNGELO et al., 2009).

No ano de 2012, o Brasil tinha 7.185.943 ha de plantios florestais de diversas espécies, em que cerca de 5.102 .030 ha $(71,0 \%)$ eram de eucalipto, 1.562 .782 ha $(21,7 \%)$, de pinus e 521.131 ha $(7,3 \%)$, de outras espécies. O Estado do Pará está entre as maiores áreas de plantios de Teca do Brasil junto dos estados de Roraima e Mato Grosso o qual se totaliza cerca de 67.329 ha $(0,9 \%)$ (ABRAF, 2013).

No entanto, verifica-se que os povoamentos de Tectona grandis L. f. apresentam produtividade extremamente variável em decorrência da diversidade de condições físicas e nutricionais do solo, combinadas com os diferentes graus de tratos culturais (SHIMIZU et al., 2007).

Os ecossistemas destinados às plantações florestais são, geralmente, de baixa fertilidade natural ou áreas com histórico de uso inadequado da terra, com desmatamento e emprego de técnicas impróprias de manejo agropecuário (GONÇALVES, 2002). Para o adequado estabelecimento das espécies florestais, é necessário que o solo permita o crescimento das raízes, o fornecimento de água e nutrientes e as trocas gasosas (CLEMENTE 
ET al., 2005).

O substrato exerce uma influência marcante na arquitetura do sistema radicular e no estado nutricional das plantas, afetando a qualidade das mudas. Por esta razão, são incorporados aos substratos, materiais que melhoram as suas características físico-químicas tornando-os mais apropriados que os materiais individuais (CALDEIRA et al., 2012).

Assim, o trabalho teve como objetivo avaliar o efeito dos substratos orgânicos na qualidade física da muda visando à implantação de um povoamento de Tectona grandis L. em Capitão Poço - PA.

\section{FUNDAMENTAÇÃO TEÓRICA}

Os compostos orgânicos podem ser utilizados como importante fonte de matéria orgânica e nutrientes para a formulação de um substrato adequado, pois estimulam o desenvolvimento de microrganismos benéficos, proporcionam aumento da capacidade de retenção de água e de nutrientes, melhoram o arejamento e a agregação do substrato às raízes das plantas e aumentam a disponibilidade de nutrientes para a muda. Os compostos atuam, também, no aumento do pH e nos teores de cátions trocáveis (WENDLING e GATTO, 2002).

A qualidade física do solo pode ser avaliada em função da habilidade das raízes em penetrarem no perfil, a qual diminui quando a densidade e a resistência do solo aumentam (REICHERT et al., 2007).

O esterco estabilizado biologicamente pode ser uma alternativa viável para misturas com outros substratos. A adubação orgânica com esterco bovino é uma prática milenar, tendo perdido prestígio com a introdução da adubação mineral (BLAISE et al., 2005).

O esterco de aves é aplicado normalmente junto com a cama, que é colocada para acomodar frangos em aviários. Este material quando bem curtido, apresenta-se bem farelado, escuro e frio, muito rico em nitrogênio e sem excesso de amônia (WEINÄRTNER et al., 2006), tornando-se um material bastante interessante na composição de um substrato.

O diâmetro do coleto é uma característica desejável das mudas, porque garante maior sustentação (TUCCI et al., 2007). Oliveira et al. (2009) enfatizam que este parâmetro deve ser utilizado como o melhor dos indicadores de padrão de qualidade das mudas, pois, com base nesse parâmetro, mudas delgadas, de grande altura, devem ser descartadas.

Kerbauy (2008) e Taiz e Zeiger (2017) enfatizam que o número de folhas é um fator inteiramente ligado ao desenvolvimento da planta, visto que elas são o principal órgão onde ocorre a fotossíntese e, também, por serem centros de reserva, fonte de auxina e cofatores de enraizamento que são translocados para a base, contribuindo, ainda, para a formação de novos 
tecidos, como as raízes, sendo por isso mais importante que os caules.

Segundo Gomes \& Paiva (2006), a massa seca aérea indica a rusticidade de uma muda, sendo que os maiores valores representam mudas mais lignificadas e rústicas, tendo maior aproveitamento em ambientes com condições adversas.

\section{METODOLOGIA}

O experimento foi montado na casa de vegetação pertencente a Universidade Federal Rural da Amazônia (UFRA), campus Capitão Poço. O município de Capitão poço está situado nas coordenadas geográficas $1^{\circ} 44^{\prime} 04.80^{\prime \prime} \mathrm{S}-4^{\circ} 03^{\prime} 23.33^{\prime \prime} \mathrm{O}$.

As sementes de teca usadas para a produção de mudas foram compradas no mês de setembro no Estado de Goiás - GO, com grau de geminação de 95\%. Para a quebra de dormência os frutos de teca foram expostos ao sol e durante a noite foram imersos em água corrente, este processo foi repetido por três dias seguidos (FIGUEIREDO et al. 2005).

No mês de dezembro, a fim de não haver interferências no experimento, os frutos foram plantados no canteiro composto de areia lavada e esterilizada a estufa a $105^{\circ} \mathrm{C}$. Assim, as sementes germinaram no final do mês de janeiro.

A composição dos substratos para a produção das mudas foi o esterco bovino, cama de frango associados às diferentes proporções de terra do subsolo. Para compor o substrato, a terra de subsolo foi peneirada em malha de $3 \mathrm{~mm}$.

Foram utilizados estercos de animais: esterco bovino (EB), cama de frango (CF). Estes foram associados a diferentes proporções de terra de subsolo (TS). Para dar mais consistência e porosidade ao substrato foram utilizados $25 \%$ de serragem, os tratamentos foram compostos pelas seguintes proporções serragem (SC), terra de subsolo (TS), esterco bovino (EB), cama de frango (CF). (SC:TS:EB:CF:): T1 (25:40:35:00); T2 (25:50:25:00); T3 (25:40:00:35); T4 (25:50:00:25).

Após atingirem altura entre cinco e sete centímetros, as plântulas foram repicadas para os sacos, preenchidos com substratos de seus respectivos tratamentos. Visando avaliar somente a influência dos substratos na nutrição das mudas, não houve qualquer adubação de base e de cobertura.

As sementes pararam de emergir em um espaço de tempo de aproximadamente 45 dias, e foi a partir do período, mais especificamente 91 dias após a semeadura que se iniciaram as avaliações biométricas das mudas, as quais eram feitas mensalmente, onde os parâmetros avaliados foram os seguintes: altura da parte aérea $(\mathrm{H})$ : a partir do nível do substrato até a inserção da última folha, com auxílio de uma régua graduada em milímetros; a 
contagem das folhas, se deram todas de forma manual.; diâmetro do coleto (D), medido na altura do colo da planta, com auxílio de um paquímetro digital; massa seca da parte aérea (MSPA), avaliada com balança digital de precisão de $0,01 \mathrm{~g}$, onde pesou-se somente a parte aérea; massa seca radicular (MSR), avaliada com balança digital de precisão de 0,01g; massa seca total; índice de qualidade de Dickson (IQD).

O turno de rega era diário, com quantidades de água variando de acordo com a necessidade hídrica das plantas.

O delineamento experimental empregado foi o inteiramente casualizado, constituindo por 4 tratamentos, com 49 repetições por tratamento sendo cada repetição constituída por uma planta, totalizando 196 plantas no total.

A massa seca total e o Índice de qualidade de Dickson (IQD) (DICKSON et al., 1960) foram calculados com em função das características morfológicas citadas, sendo a MST determinada pela soma da MSPA e MSR, e o IQD calculado através da fórmula 1:

$$
I Q D=\frac{M S T}{H / D+M S P A / M S R}
$$

Para as análises físicas dos substratos foram amostrados três sacos de polietilenc as respectivas formulações de cada tratamento. Esses substratos permaneceram na casa de sombra durante 150 dias, submetido às mesmas condições de desenvolvimento das mudas. Em seguida, foram retirados do saco o solo em formato de anéis com altura de cerca de $5 \mathrm{~cm}$ e envolvidos com tecido tipo "filó" de malha fina enlaçados com elástico de borracha para análise física. No entanto, para a análise química foram pesados $250 \mathrm{~g}$ de solo de cada tratamento.

Na tabela 1 a análise química dos tratamentos que foi determinada no Laboratório da Embrapa Amazônia Oriental, Belém, PA, conforme metodologia da EMBRAPA (1999).

Tabela 1: Resultados da análise química dos substratos utilizados para produção de mudas de Tectona grandis L.

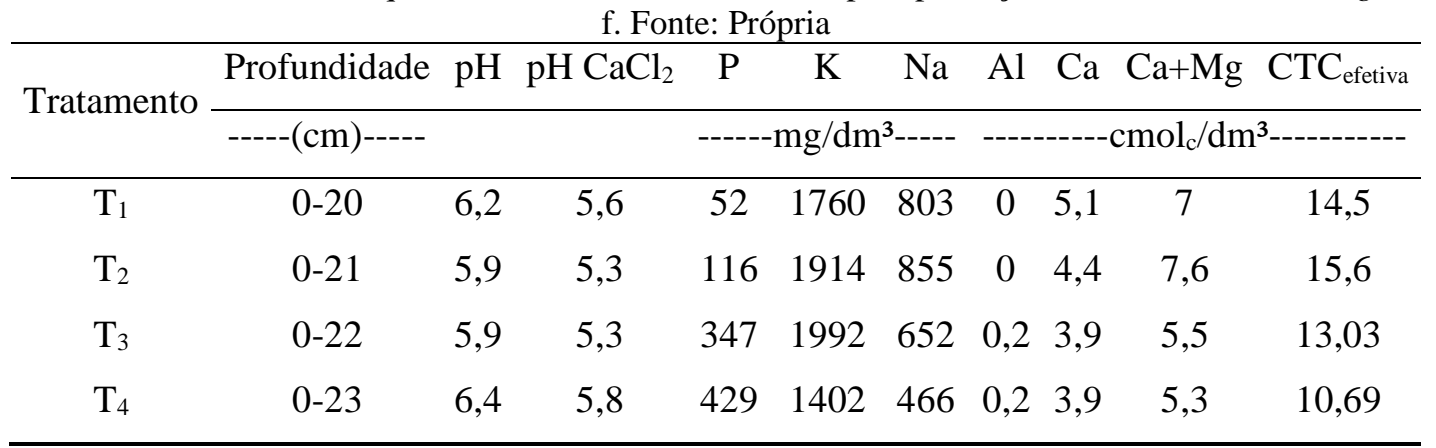

CTC: capacidade de troca catiônica;

As características biométricas foram submetidas ao teste de normalidade de ShapiroWilk, em seguida a análise de variância e após significância do teste $\mathrm{F}(\mathrm{p}<0,05)$ as médias 
foram comparadas pelo teste Tukey no programa estatístico SISVAR versão 5.6 (FERREIRA, 2011).

\section{RESULTADOS E DISCUSSÃO}

$\mathrm{Na}$ Figura 1, observou-se que o uso de esterco bovino e cama de frango como componente de substrato proporcionou efeito significativo $(\mathrm{p}<0,05)$ para as variáveis: altura da parte aérea, número de folhas e diâmetro do coleto. Com exceção para o número de folhas que foram estatisticamente iguais nos 151 dias após a semeadura (DAS). O coeficiente de variação do variável número de folhas foi alto no período de 91 DAS, isso pode ser explicado pela grande quantidade de formiga cortadeira no início do experimento (Tabela 2).

Figura 1: Altura da parte aérea, número de folhas e diâmetro do coleto nas mudas de teca produzidas em diferentes substratos e diferentes períodos sendo 91 (A), 121 (B) e 151 (C) dias após a semeadura (DAS). Letras diferentes acima das colunas indicam diferenças significativas pelo Teste de Tukey $(\mathrm{p}<0,05)$. Fonte: Própria
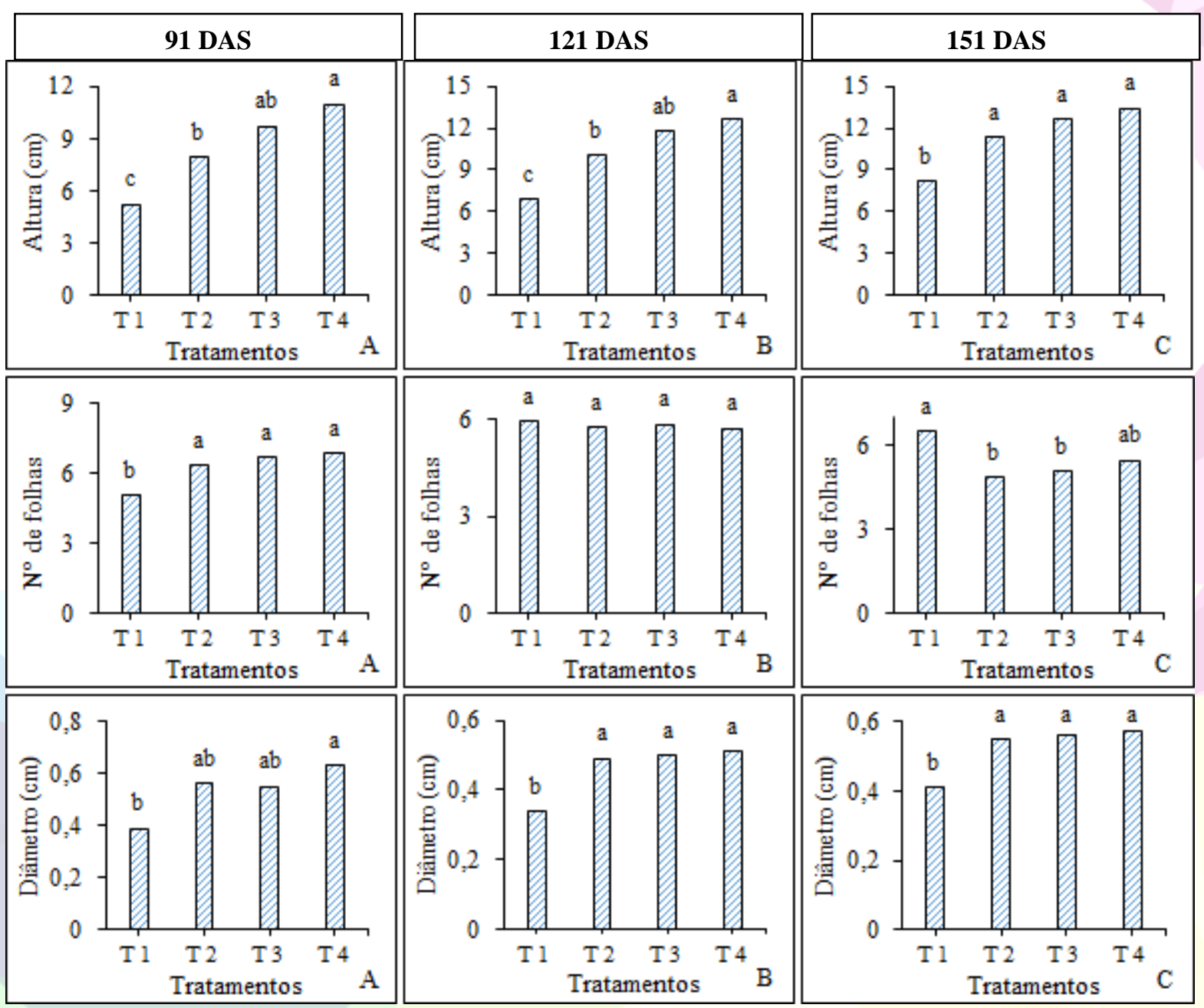
Tabela 2: Coeficientes de variações nas variáveis altura, diâmetro e nº de folhas nos períodos 91, 121 e 151 dias após a semeadura (DAS) pelo teste de variância a $5 \%$ de probabilidade. Fonte: Própria

\begin{tabular}{cccc}
\hline \multirow{2}{*}{ Variáveis } & \multicolumn{3}{c}{$\mathrm{CV}(\%)$} \\
\cline { 2 - 4 } & $91 \mathrm{DAS}$ & $121 \mathrm{DAS}$ & $151 \mathrm{DAS}$ \\
\hline Altura & 0,43 & 0,42 & 0,37 \\
Diâmetro & 0,24 & 0,38 & 0,37 \\
$\mathrm{~N}^{\mathbf{o}}$ de folhas & 0,57 & 0,26 & 0,29 \\
\hline
\end{tabular}

CV: coeficiente de variação.

As mudas apresentaram crescimento médio em altura entre 5,24 a 10,97; 6,95 a 12,62; 8,2 a 13,44 $\mathrm{cm}_{\text {planta }}{ }^{-1}$ para os períodos de 91, 121 e 151 DAS, respectivamente. A maior média ocorreu no tratamento T4, sendo estatisticamente igual ao tratamento T3 em todos os períodos analisados. O tratamento T1 apresentou as menores médias em altura em todos os períodos.

O crescimento em diâmetro das mudas de teca variou de 0,39 a 0,$63 ; 0,34$ a 0,$51 ; 0,41$

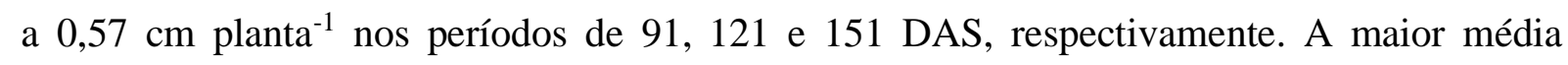
ocorreu no tratamento T4 e T3 sendo estatisticamente iguais em todos os períodos. Os tratamentos T1 apresentou as menores média em crescimento em diâmetro. Com exceção no período de 91 DAS que o tratamento T1 se igualou estaticamente com o tratamento T2, T3 e T4.

O número das folhas das mudas de teca variou de 5,08 a 6,89; 5,73 a 5,95; 4,84 a 6,5 nos períodos de 91, 121 e 151 DAS, respectivamente. No 91 e 121 DAS as médias não se diferenciaram entre si, com exceção do tratamento T1 que no 91 DAS foi diferente estatisticamente dos demais. No 60 DAS o tratamento T4 e T2 obtiveram as melhores médias. No entanto o tratamento T2 e T3 se igualou estatisticamente ao T4 neste mesmo período.

Este decréscimo foliar no mínimo pode ter ocorrido porque neste período, as mudas foram atacadas por formigas, propiciando a queda de algumas folhas, onde o tratamento T4 foi o mais atacado.

Isso também pode ter influenciado na desigualdade entre os tratamentos para 151 DAS. Que apesar de terem aumentado seu número de folhas, acabaram perdendo algumas, por terem sido atacadas por esta praga, o que fez com que o coeficiente de variação apresentasse valor tão elevado, em relação aos demais.

Testando a cama de frango associada à terra de subsolo como substrato para a produção de mudas de tamarindeiro, Pereira et al. (2010) concluíram que a melhor proporção para o crescimento dessas mudas foi $60 \%$ de terra de subsolo $+40 \%$ de cama de frango, resultando em plantas de vigoroso crescimento em altura e diâmetro. 
Assim como para as variáveis altura e diâmetro, os tratamentos formados com cama de frango resultaram em maiores ganhos em biomassa aérea e radicular. No entanto para o número de folhas aos 121 DAS tanto os tratamentos formados por cama de frango quanto por esterco bovino foram iguais estatisticamente.

Ao avaliar parâmetros como altura, diâmetro do coleto, número de folhas, área foliar e matéria seca de mudas de Calophyllum brasiliense, Artur et al. (2007) registraram uma diminuição desses parâmetros inversamente proporcional à adição de esterco bovino ao substrato. Da mesma forma, Silva et al. (2013) registraram menor crescimento em mudas de Ormosia arborea após a adição de esterco bovino ao substrato, assim como Melo et al. (2014) para a produção de mudas de Eremanthus erythropappus. No entanto, estes mesmos autores, verificaram melhoria na qualidade de mudas de Eucalyptus grandis com o acréscimo do percentual de esterco ao substrato.

Na Figura 2, mostra a massa seca da parte aérea (Msa), Massa seca da parte radicular (Msr) e Massa seca total (Mst) das mudas de teca com relação aos substratos orgânicos. O tratamento composto por substratos orgânicos influenciou significativamente as variáveis estudadas. O coeficiente variação foi o mesmo para todas as variáveis analisadas (Tabela 3).

Figura 2: Massa seca da parte aérea (Msa), Massa seca da parte radicular (Msr) e Massa seca total (Mst) das mudas de teca produzidas em diferentes substratos no 151 (DAS) dias após a semeadura. Letras diferentes acima das colunas indicam diferenças significativas pelo Teste de Tukey $(\mathrm{p}<0,05)$. Fonte: Própria

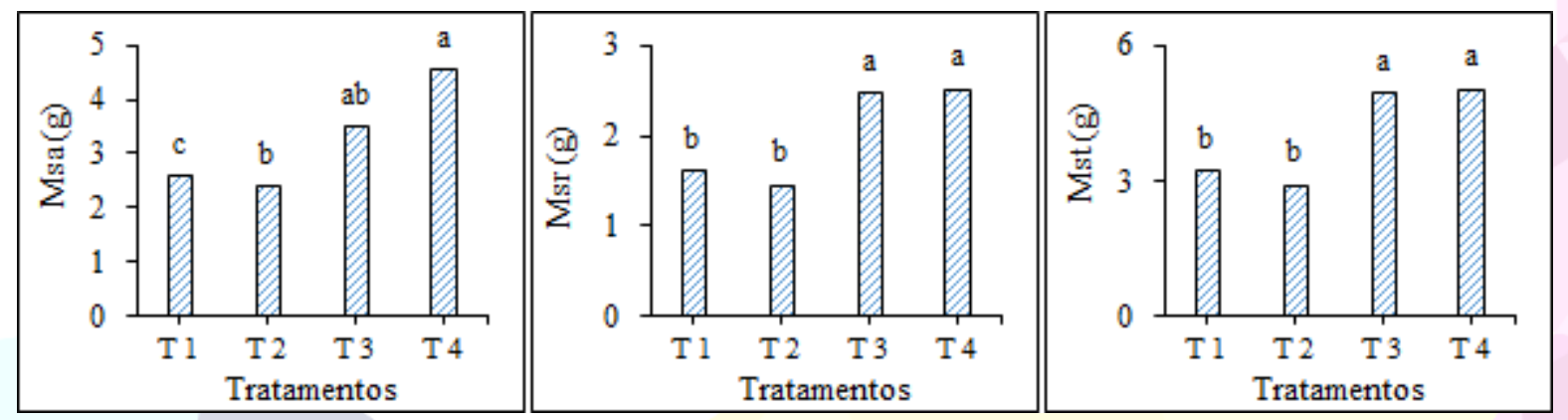

Tabela 3: Coeficientes de variações (CV) nas variáveis massa seca da parte aérea, radícula e o total no período de 151 dias após a semeadura (DAS) pelo teste de variância a 5\% de probabilidade. Fonte: Própria

\begin{tabular}{cc}
\hline \multirow{2}{*}{ Variáveis } & CV $(\boldsymbol{\%})$ \\
\cline { 2 - 2 } & $151 \mathrm{DAS}$ \\
\hline MSA & 0,08 \\
MSR & 0,08 \\
MST & 0,08 \\
\hline
\end{tabular}

A massa aérea das mudas de teca variou de 2,41 a 4,55 $\mathrm{g}^{\text {planta }}{ }^{-1}$. A maior média ocorreu no tratamento T3 e T4 sendo estatisticamente iguais. O tratamento T2 se igualou estatisticamente ao tratamento T3 e o tratamento T1 foi que apresentou a menor média. 
A massa seca radicular das mudas de teca variou de 1,45 a 2,51 $\mathrm{g}$ planta $^{-1}$. A maior média ocorreu no tratamento T3 e T4 sendo estatisticamente iguais. O tratamento T1 e T2 foi que apresentou a menor média.

Para a massa seca total, os resultados não foram diferentes da massa seca radicular. As mudas alcançaram valores entre 2,91 a 5,02 $\mathrm{g} \mathrm{planta}^{-1}$, sendo o maior valor obtido nos tratamentos iguais estatisticamente $\mathrm{T} 3$ e $\mathrm{T} 4$. E os tratamentos $\mathrm{T} 1$ e $\mathrm{T} 2$ promoveram estatisticamente o menor incremento de biomassa total nas mudas de teca.

Avaliando a figura 3 é possível observar as médias do índice de qualidade de Dickson (IQD) das mudas de teca, tendo o comportamento das plantas originárias de substratos composto de esterco bovino os menores valores em média para o IQD. Com coeficiente de variação igual a 30,9\%.

Figura 3: Índice de qualidade de Dickson (IQD) das mudas de teca produzidas em diferentes substratos no 151 (DAS) dias após a semeadura. Letras diferentes acima das colunas indicam diferenças significativas pelo Teste de Tukey $(\mathrm{p}<0,05)$. Fonte: Própria

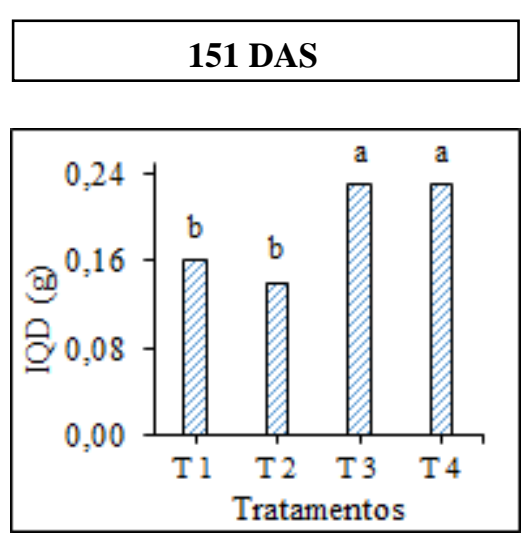

Os valores de IQD das mudas de teca alcançaram valores entre 0,14 a 0,23 . As maiores médias foram encontradas nos tratamentos T3 e T4. Já os tratamentos T1 e T2 apresentaram as menores médias de IQD nas mudas de teca.

As características morfológicas e os índices de qualidade das mudas avaliadas neste experimento apresentaram respostas distintas entre si. Pela análise estatística, observou-se efeito significativo dos substratos em todas as características analisadas, exceto no número de folhas no período de 30 DAS onde todos os tratamentos se igualaram entre si.

\section{CONCLUSÕES}

A composição com substratos orgânicos para a produção de teca (T. grandis) exerceu influência nas características morfológicas e consequentemente no índice de qualidade de Dickson das mudas. As plantas mais desenvolvidas foram produzidas no tratamento T4 composto de $25 \%$ de serragem $+50 \%$ de subsolo $+25 \%$ de esterco de frango. 


\section{REFERÊNCIAS}

ABRAF - Associação Brasileira de Produtores de Florestas Plantadas. Anuário Estatístico da ABRAF 2013 - ano base 2012. Brasília, 2013. 142p.

ARTUR, A. G. et al. Esterco bovino e calagem para formação de mudas de guanandi. Pesquisa Agropecuária Brasileira, v. 42, n. 6, p. 843-850, 2007.

ÂNGELO, H.; SILVA, V. S. de M.; SOUZA, Á. N. de; GATTO, A. C. Aspectos financeiros da produção de teca no Estado de Mato Grosso. Floresta, v. 39, n. 1, p. 23-32, 2009.

BEZERRA, A.; MILAGRES, F. R.; SILVA, R. L.; LEITE, H. G. Análise da viabilidade econômica de um povoamento de Tectona grandis submetidos a desbastes no Mato Grosso. Cerne, Lavras, v. 17, n. 4, p. 583-592, out./dez., 2011.

BLAISE, D. et al. Effects of farmyard manure and fertilizers on yield, fibre quality and nutrient balance of rainfed cotton (Gossipium hirsutum). Bioresource Technology, v. 96, p. 345-349, 2005.

CALDEIRA, Marcos Vinicius Winckler et al. Biossólido na composição de substrato para a produção de mudas de Tectona grandis. Floresta, v. 42, n. 1, p. 77-84, 2012.

CLEMENTE, E. P. et al. Soil compaction around Eucalyptus grandis roots: a micromorphological study. Australian Journal of Soil Research. v. 43, n. 2, 139-146, Mar. 2005.

DICKSON, Alexander; LEAF, Albert L.; HOSNER, John F. Quality appraisal of white spruce and white pine seedling stock in nurseries. The Forestry Chronicle, v. 36, n. 1, p. 10-13, 1960.

EMBRAPA. Sistema brasileiro de classificação de solos. Rio de Janeiro, v. 412, 1999.

FIGUEIREDO, E. O.; OLIVEIRA, A. D.; SCOLFORO, J. R. S. Análise econômica de povoamentos não desbastados de Tectona grandis L.f. na microrregião do baixo rio Acre. Cerne, Lavras, v. 11, n. 4, p. 342- 353, 2005.

FERREIRA, Daniel Furtado. Sisvar: a computer statistical analysis system. Ciência e agrotecnologia, v. 35, n. 6, p. 1039-1042, 2011.

GONÇALVES, J. L. M. Principais solos usados para plantações florestais. In: GONÇALVES, J. L. M.; STAPE, J. L. Conservação e cultivo de solos para plantações florestais. Piracicaba: IPEF, 2002, cap. 1, p.1-46.

GOMES J. M, PAIVA H. N. Viveiros florestais: propagação sexuada. Viçosa: UFV. 2006.

KERBAUY, G. B. Fisiologia vegetal. 2. ed. Rio de Janeiro: Guanabara Koogan, 446 p. 2008.

MISSOURI BOTANICAL GARDEN, 2013. Tectona grandis L.f. Acesso em: http://www.tropicos.org/Name/33700544. Acesso em: 16 de março de 2017.

MELO, L. A. et al. Crescimento de mudas de Eucalyptus grandis e Eremanthus 
erythropappus sob diferentes formulações de substrato. Floresta e Ambiente, v. 21, n. 2, p. 234-242, 2014.

OLIVEIRA, A.B. de; MEDEIROS FILHO, S.; BEZERRA, A.M.E.; BRUNO, R. de L.A. Emergência de plântulas de Copernicia hospita Martius em função do tamanho da semente, do substrato e do ambiente. Revista Brasileira de Sementes, Brasília, v.31, n.1, p.281-287, 2009.

PEREIRA, P. C. et al. Mudas de tamarindeiro produzidas em diferentes níveis de matéria orgânica adicionada ao substrato. Revista Verde, Mossoró, v. 5, n. 3, p. 152-159, 2010.

REICHERT, J. M. et al. Compactação do solo em sistemas agropecuários e florestais: identificação, efeitos, limites críticos e mitigação. In: CERRETA, C. A.; SILVA, L. S. da; REICHERT, J. M. (Ed.). Tópicos em ciência do solo. Viçosa: Sociedade Brasileira de Ciência do Solo, 2007. v.5. p. 49-134.

SHIMIZU JY.; KLEIN, H.; OLIVEIRA, JRV. Diagnóstico das plantações florestais em Mato Grosso. Cuiabá: Central de Texto; 2007.

SILVA, A. L. et al. Influência de diferentes substratos no crescimento inicial de Ormosia arborea (Vell.) Harms (Fabaceae). Revista Verde de Agroecologia e Desenvolvimento Sustentável, v. 8, n. 4, p. 22-27, 2013.

TUCCI, M.L.S.; BOVI, M.L.A.; MACHADO, E.C.; SPIERING, S.H. Seasonal growth variation of peach palms cultivated in containers under subtropical conditions. Scientia agrícola, Piracicaba, v.64, n.2, p.138-146, 2007.

TAIZ, Lincoln et al. Fisiologia e desenvolvimento vegetal. Artmed Editora, 2017.

WEINÄRTNER, M. A.; ALDRIGHI, C. F. S.; MEDEIROS, C. A. B. Adubação Orgânica. Pelotas, 2006.

WENDLING, I.; GATTO, A. Substratos, adubação e irrigação na produção de mudas. Viçosa: Aprenda fácil. 2002. 